\title{
Causos e Estórias: Uma abordagem interdisciplinar como recurso metodológico importante no processo de ensino-aprendizagem e formação de leitores literários
}

Guilhermina Reis da Silva ${ }^{1}$; Thuany Cristina dos Santos Pereira² ;

Elane Andrade ${ }^{3}$; Geraldo Sadoyama ${ }^{4}$; Leonardo Santos Andrade ${ }^{5}$,

Paulo Alexandre de Castro6; Adriana dos Santos Prado Sadoyama7

\section{Resumo}

Por meio das leituras e investigação, percebe-se que a interdisciplinaridade ainda é motivo de discussões principalmente no que se refere às práticas pedagógicas que envolvam o tema. As escolas, de um modo geral, principalmente as de ensino básico, permeiam o seu trabalho de maneira fragmentada sem que haja realmente a dialética entre a teoria e o fazer. Nessa proposta de projeto, são feitas reflexões acerca das possibilidades de efetivação das práticas interdisciplinares utilizando-se os causos e estórias como recursos metodológicos em sala de aula. $O$ trabalho tem como objetivo desenvolver práticas interdisciplinares a partir do gênero textual causos e incentivar a formação de leitores literários. Foram

\footnotetext{
${ }^{1}$ Professora Supervisora do PIBID Interdisciplinar/Regional Catalão/UFG guilhermina.silva62@gmail.com

2Discente do PIBID Interdisciplinar/Regional Catalão/UFG. thuanycristinne@gmail.com

3 Discente do PIBID Interdisciplinar/Regional Catalão/UFG. elaneandrade907@gmail.com

4 Coordenador de Área do Subprojeto Interdisciplinar - (PIBID, UFG/RC), E-mail: gsadoyama@yahoo.com.br

5 Coordenador de Área do Subprojeto Interdisciplinar - (PIBID, UFG/RC), E-mail: Is_andrade@yahoo.com.br

${ }_{6}$ Coordenador de Área do Subprojeto Interdisciplinar - (PIBID, UFG/RC), E-mail: padecastro@ufg.br

7 Coordenadora de Área do Subprojeto Interdisciplinar - (PIBID, UFG/RC), E-mail: drisadoyama@gmail.com
} 
realizadas pesquisas referentes ao tema, revisão bibliográfica e teste piloto com trinta e seis alunos do quinto ano do Colégio Estadual Anice Cecílio Pedreiro, no município de Catalão - GO. Os alunos responderam um questionário sobre o hábito da leitura e resolveram atividades interdisciplinares sobre os vídeos apresentados: $O$ causo da Melancia, O causo do Ovo e o Causo da bicicleta. Essas atividades envolveram as disciplinas de ciências, geografia, história e matemática. Após a exposição dos vídeos, uma melancia foi fracionada em duas, três, quatro, oito partes e os alunos tiveram a oportunidade de revisar frações e reforçar conceitos matemáticos. Uma roda de contação de causos trazidos pelos alunos e ilustrações dos mesmos, complementou a ação pedagógica. Espera-se que os alunos melhorem a escrita, a oralidade e a leitura uma vez que, através das correções das atividades propostas, percebeu-se que a turma apresenta relativa dificuldade na leitura, escrita e interpretação de texto. Além disso, observou-se que, apenas uma pequena parcela dos estudantes tem 0 hábito da leitura. Essa abordagem interdisciplinar permite a conexão e dialética entre os vários campos do saber. Sendo assim, a leitura, a escuta e a escrita se tornam elementos essenciais no processo de ensino-aprendizagem e formação de leitores literários. Após a aplicação das atividades verificou-se um grande interesse dos alunos em pesquisar, participar das aulas, apresentar e encenar causos e melhorar o aprendizado. Conclui-se que a continuação do trabalho poderá trazer bons resultados na efetivação da prática interdisciplinar e principalmente na formação de leitores literários.

Apoio: PIBID/CAPES

Palavras-Chave: Estórias e causos; interdisciplinaridade; leitores literários 